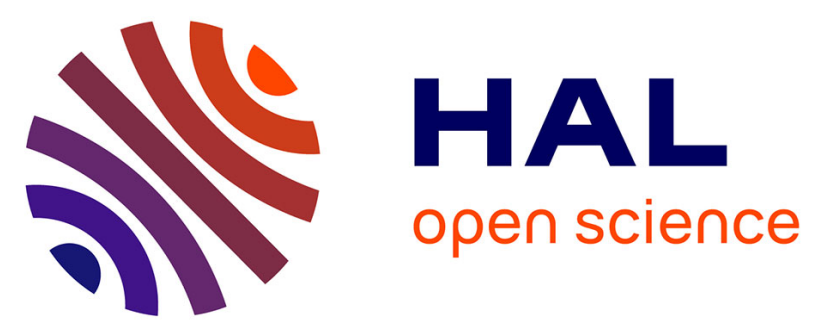

\title{
Comparison of Symptom Control in Pediatric Gastroparesis using Endoscopic Pyloric Botulinum Toxin Injection and Dilatation
}

Delphine Ley, Madeleine Aumar, Julie Lemale, Alexandre Fabre, Stéphanie Colinet, Alain Duhamel, Frédéric Gottrand, Clémence Mercier

\section{To cite this version:}

Delphine Ley, Madeleine Aumar, Julie Lemale, Alexandre Fabre, Stéphanie Colinet, et al.. Comparison of Symptom Control in Pediatric Gastroparesis using Endoscopic Pyloric Botulinum Toxin Injection and Dilatation. Journal of Pediatric Gastroenterology and Nutrition, 2021, Publish Ahead of Print, 10.1097/MPG.0000000000003195 . hal-03261412

\section{HAL Id: hal-03261412 \\ https://hal.sorbonne-universite.fr/hal-03261412}

Submitted on 15 Jun 2021

HAL is a multi-disciplinary open access archive for the deposit and dissemination of scientific research documents, whether they are published or not. The documents may come from teaching and research institutions in France or abroad, or from public or private research centers.
L'archive ouverte pluridisciplinaire HAL, est destinée au dépôt et à la diffusion de documents scientifiques de niveau recherche, publiés ou non, émanant des établissements d'enseignement et de recherche français ou étrangers, des laboratoires publics ou privés. 


\section{Comparison of Symptom Control in Pediatric Gastroparesis using Endoscopic Pyloric Botulinum Toxin Injection and Dilatation}

Authors:

Clémence Mercier1, MD; Delphine Ley1, MD; Madeleine Aumar1, MD; Julie Lemale2, MD; Alexandre Fabre3, MD; Stéphanie Colinet4, MD; Alain Duhamel5, MD, PhD; Frédéric Gottrand1, MD, PhD.

1. Univ. Lille, Inserm, U1286 - Infinite, CHU Lille, Division of Pediatric Gastroenterology, Hepatology and Nutrition, Department of Pediatrics, F-59000 Lille, France

2. Department of Pediatric Nutrition and Gastroenterology, Trousseau Hospital-APHP, Sorbonne University, Paris

3. APHM, Timone Enfant, Service de pédiatrie multidisciplinaire, AP-HM, Marseille, France Aix Marseille Univ, INSERM, MMG, Marseille, France

4. Gastroentérologie pédiatrique, Montlégia Hospital, CHC, Liège, Belgique

5. Unité de Méthodologie, Biostatistique et Data Management, CHU de Lille, France

Corresponding author: Clémence MERCIER, MD, clemence-mercier@ hotmail.fr

\section{Disclosure:}

Authors have no conflicts of interest or financial ties to disclose: Drs. Mercier, Ley, Aumar, Lemale, Fabre, Colinet, Duhamel and Gottrand have no conflicts of interest or financial ties to disclose.

Funding sources: none

This work is dedicated in memoriam of Dr Laurent Michaud. 


\section{Comparison of Symptom Control in Pediatric Gastroparesis using Endoscopic Pyloric Botulinum Toxin Injection and Dilatation}

\section{Abstract}

Objectives The objective of this study was to assess the tolerance and efficacy of endoscopic intrapyloric botulinum toxin injection compared with pyloric dilatation in children with gastroparesis.

Methods This was a retrospective descriptive multicentre study that included pediatric patients treated between 2010 and 2018 at four tertiary hospitals.

Results Data were collected for 24 patients. The median age at diagnosis was 2.5 years (range 0.5-4.7). A total of 46 endoscopic procedures were performed. The endoscopic procedure was multiple in $63 \%$ of patients. Among the interventions, $76 \%$ were successful and $15 \%$ were unsuccessful. The recurrence rate was $57 \%$ and the median time to recurrence was 3.7 months (0.1-73). The efficacy did not differ significantly between the two methods at the first intervention and as a second-line treatment. The recurrence rate also did not differ significantly between the two methods. No complications were reported. The median followup was 19.8 months (1.7-61.7).

Conclusions In this retrospective multicentre study, endoscopic management of gastroparesis by balloon dilatation or botulinum toxin was safe in children and seemed to be partially efficient within the first months. Symptoms recurred frequently and required repetition of the interventions.

Keywords Gastroparesis, Child, Endoscopy, Botulinum toxin, Pyloric, Balloon dilatation 


\section{What is known?}

- Gastroparesis in child is infrequent and treatment is far from being consensual.

- Endoscopic procedures are available, such as pyloric balloon dilatation or botulinum toxin injection.

\section{What is new?}

- Endoscopic procedures of pyloric balloon dilatation and toxin botulinum injection are safe.

- There is no superiority of either treatment.

- Effectiveness is short-term and transitory. 


\section{Introduction}

Gastroparesis in children is a rare entity and its prevalence is unknown [1]. Although the etiologies are multiple, gastroparesis in children is frequently idiopathic [2]. The diagnosis is based on clinical signs (nausea, vomiting, abdominal pain, failure to thrive) and a scintigraphy gastric-emptying study is the reference examination [3]. There is at present no consensus about the best treatment in children, which is complex and involves dietary measures, drug therapy (antiemetics, prokinetics), enteral or parenteral nutrition, and often endoscopic and surgical techniques. In the past few years, advances in endoscopic techniques have focused on the hypertonic component and relaxation anomalies of the pylorus and include intrapyloric injection of botulinum toxin [4], mechanical pyloric dilatation [5] and, more recently, gastric pyloromyotomy [6]. Experience of the use of these techniques in children remains limited [7]. Despite limited data in children, these techniques are occasionally used to improve the clinical impact of gastroparesis in these patients. Their main advantages are simplicity and ease of use, low risk, and the possibility of repeated procedures if needed.

The objective of this study was to examine the tolerance and efficacy of endoscopic intrapyloric botulinum toxin injection compared with pyloric dilatation in children with gastroparesis.

\section{Materials and methods}

This was a retrospective descriptive multicentre study. Four centres participated: Jeanne de Flandre Lille University Children's Hospital (Lille, France); Trousseau Hospital (Paris, France); La Timone Hospital (Marseille, France); and Christian Hospital (Liège, Belgium).

\section{Patients}

All patients younger than 18 years with gastroparesis who received endoscopic treatment involving pyloric dilatation and/or botulinum toxin injection between 2010 and 2018 were 
included consecutively. There were no exclusion criteria. The diagnosis of gastroparesis was based on the combination of clinical symptoms and at least one of the following objective signs of slow gastric emptying: scintigraphy evidence of delayed gastric emptying based on the retention values (liquid and/or solid scintigraphy, reference for gastric retention value: residue $>90 \%$ at $1 \mathrm{~h}, 60 \%$ at $2 \mathrm{~h}$, and $10 \%$ at $4 \mathrm{~h}$, based on the adult standardized values) or observations from an gastrointestinal transit study (delayed gastric emptying, gastric distension). All children underwent gastroscopy to rule out obstruction.

\section{Procedures}

All procedures were performed with the patient under general anaesthesia and with orotracheal intubation under endoscopic control. Botulinum toxin was diluted with saline serum and injected using a sclerotherapy needle into the four quadrants of the pyloric mucosa at a dose of $6 \mathrm{IU} / \mathrm{kg}$ (maximum $100 \mathrm{IU}$ per child per injection). Dilatation was performed using hydrostatic balloons of increasing size from 6 to $20 \mathrm{~mm}$. The size was adapted to the child's weight and age (balloons $<10 \mathrm{~mm}$ in diameter were used for weight $<10 \mathrm{~kg}, 10$ to 20 $\mathrm{mm}$ in diameter for children weight from 10 to $30 \mathrm{~kg}$, and $20-22 \mathrm{~mm}$ for weight $>30 \mathrm{~kg}$ ). The dilatation time was set at one minute, the effectiveness being judged on the dilaceration and the increase in the diameter of the pylorus. Each patient could receive different interventions over time (e.g., botulinum toxin followed by dilatation or vice versa); the choice was at the discretion of the clinician.

Intervention success was defined $a$ priori as a clinical improvement occurring during the immediate postoperative period (within 1 week after the intervention). Success was considered as total when there were no more digestive symptoms after the intervention and partial when symptoms improved partially but not fully. Failure of intervention was defined $a$ priori as unchanged symptoms and/or the need for a new treatment in the immediate 
postintervention period. Recurrence was defined as the reappearance of symptoms at least 1 week after a successful intervention.

\section{Statistical analysis}

Categorical variables are expressed as percentages and continuous variables are expressed as mean and standard deviation or median, quartiles, and minimum/maximum values. Fisher's exact test or the Wilcoxon signed-rank test was used to compare the two treatment groups (pyloric dilatation versus botulinum toxin injection at the first intervention). A trend test was used to compare the efficacy between the two techniques. The alpha level was set at $5 \%$.

\section{Ethical considerations}

IRB approval was not required. Because the study was observational and the data were obtained without any additional intervention or monitoring procedure and according to French regulations on research, formal ethics committee approval was not required [8]. Nevertheless, parents and children received written information about the study. The data was de-identified.

\section{Results}

\section{Demographics}

Twenty-four patients were included (Table 1). Median age at diagnosis was 2.5 years (range 0.5-4.7). Twenty children had chronic symptoms for at least 6 months $(83 \%)$. There were no significant differences in demographic characteristics between the two treatment groups at the first intervention.

Treatment before endoscopy included dietary measures (split meals, low fibres and lipids content) in six patients (25\%), enteral nutrition in 10 patients $(42 \%)$, and parenteral nutrition in two patients. Drug therapy was prescribed in 23 patients: proton pump inhibitors (PPIs, $\mathrm{n}=$ 19/24, 79\%), prokinetics (erythromycin or domperidone: $\mathrm{n}=15 / 24 ; 62 \%$ ), and antiemetics in only one patient. Drug therapy was considered unsuccessful in 13/23 patients (57\%). 


\section{Endoscopic procedures}

Table 2 shows the results of the endoscopic procedures. A total of 46 endoscopic procedures were performed. The median age at the first intervention was 2.9 years (range 1-5.8). The endoscopic procedure was performed once in nine patients (37\%) and at least once more in the other 15 patients $(63 \%)$ : twice in eight patients $(8 / 24,33 \%)$, three times in six patients $(6 / 24,25 \%)$, and four times in one patient. Balloon dilatation alone was used in 12 patients $(50 \%)$. Botulinum toxin alone was used in six patients $(25 \%)$. Six patients $(25 \%)$ received both endoscopic techniques consecutively because of failure or recurrence after the previous procedure.

Success was undocumented in four interventions. Success was observed in 35 interventions $(76 \%)$, either total $(13 / 35,37 \%)$ or partial $(22 / 35,63 \%)$ and failure was observed in the remaining seven interventions (15\%). The recurrence rate was 57\%. The median time to recurrence was 3.7 months (range $0.2-73$ ).

Table 3 shows a comparison between the two treatment groups. The patient characteristics did not differ between groups. The efficacy of treatment did not differ significantly between the two methods at the first and second intervention or when all interventions were combined. Similarly, the rate of recurrence did not differ significantly between the two methods.

After the first procedure, only 5 patients underwent a re-evaluation scintigraphy because of clinical recurrence (all remained abnormal). Because few patients had an objective reevaluation study of the gastroparesis after the intervention, evaluation of the results was based on clinical criteria such as weight and height gain, frequency of vomiting and weaning from enteral/parenteral nutrition.

No complications such as perforation, haemorrhage or sepsis were reported in either of the treatment groups. 


\section{Follow-up}

The median follow-up time was 19.8 months (range 1.7-61.7). One patient was lost to followup. One child had a history of neurofibromatosis and died of an unknown reason at 21 months of age, 16 months after the procedure (botulinum toxin).

At the last follow-up consultation, 12 patients still had symptoms suggestive of gastroparesis such as nausea, vomiting, abdominal pain, or failure to thrive (12/22, 55\%). Anthropometric parameters (weight, height, body mass index (BMI), and Z scores) did not differ between the date of diagnosis and the last visit.

Oral feeding was possible in $87 \%$ of patients and was associated with enteral nutrition in $39 \%$ of patients. No child required parenteral nutrition. Five patients had oral feeding difficulties (23\%). Drug therapy was prescribed in $52 \%$ of patients, $48 \%$ of whom were given PPIs. Three patients required secondary surgical treatment at the age of 5,8 , and 11 years: two received a gastric peroral endoscopic pyloromyotomy (G-POEM) and one received a surgical pyloroplasty. No surgical complications were reported.

\section{Discussion}

Childhood gastroparesis is a rare and poorly investigated disorder that is difficult to manage. Endoscopic techniques have been developed but are poorly described in the pediatric population. There are few studies reporting on the safety and efficacy of endoscopic management of pediatric gastroparesis $[9,10]$. To our knowledge, this observational study is the first to compare the results of balloon dilatation and botulinum toxin injection.

In this series, these two endoscopic techniques appeared to be safe, and no complications were reported in the short, medium, or long term. Despite the small size of this sample and the retrospective and multicentric nature of the study, we found no obvious difference in efficacy between the two methods. However, the efficacy of these procedures was transient and early recurrence was frequent. 
These results are consistent with those of other pediatric studies. However our study differs from others $[2,11]$ by the significant lower age of our population $(2.5$ years compared to 7.9 to 9 years); this may lead to different outcomes since etiologies, duration of gastroparesis and its transient or permanent nature, as well as treatment modalities may differ.

Endoscopic treatments of gastroparesis have produced contradictory results in adult patients. Retrospective studies show a temporary efficacy of botulinum toxin that correlates with age $<50$ years, female sex, idiopathic cause, toxin dosage, and repeated administration [12]. In randomized double-blind studies, toxin was no more effective than placebo $[13,14]$. These studies involved a small number of patients (31 and 32 patients, respectively) and were based on scintigraphy data and not on data about clinical efficacy [15]. The heterogeneous results of botulinum toxin may be explained, in part, by the pyloric anatomy, which leads to diffusion of the product into adjacent areas [16]. The European Society of Gastrointestinal Endoscopy (ESGE) recommends against botulinum toxin injection in the treatment of unselected adult patients with gastroparesis. The ESGE stipulates that the toxin should be considered only in patients with symptoms suggestive of gastroparesis in combination with objective proof of delayed gastric emptying in a validated test, and only when medical therapy has failed [17]. Botulinum toxin is recommended only for adult patients with refractory gastroparesis, which is defined as gastroparesis refractory to several pharmacological treatments for at least 1 year. This is due to safety and simplicity of toxin administration [18], which may allow for avoidance of the need for more invasive surgical treatment [15].

In 2012, Rodriguez et al. reported a retrospective series of 47 pediatric patients with gastroparesis who received a total of 70 botulinum toxin injections [10]. The authors reported that $67 \%$ of the patients had a partial or total response but that the mean duration of the 
response was only 3 months. More recently, Hirsch et al. reported a retrospective of 85 pediatric patients with gastroparesis who received a total of 118 botulinum toxin injections : the rate of effectiveness was similar and injections allowed an improvement in feeding with fewer patient needing post pyloric feeds after injections compared with before [19].

In adults, pyloric balloon dilatation is not recommended for the treatment of gastroparesis [17]. This procedure was first described in children with pyloric obstruction [20], peptic stenosis [21], or caustic stenosis of the esophagus [22]. Israel et al. reported a retrospective pediatric series of 19 patients with gastroparesis who underwent pyloric dilatation. Thirteen patients had complete resolution of symptoms and five patients experienced transient improvement requiring additional surgical treatment [9]. As for botulinum toxin, the longterm effectiveness of pyloric dilatation seems to be limited [23].

Taken together, our results and those of previous studies suggest that these two endoscopic treatments are transiently effective by providing an initial improvement, which may serve as a bridge to spontaneous resolution of gastroparesis or to the need for more invasive management.

As our study was not randomized, we cannot exclude that the natural history of gastroparesis or a placebo effect could explain the efficacy of endoscopic intervention. However, most of the patients reported herein had a long duration of symptoms and failure of several drugs and enteral nutrition with a significant impact on nutritional status and growth before they underwent endoscopic treatment. More than $2 / 3$ of the patients clinically improved, could be discharged from hospital or further be weaned from parenteral nutrition suggesting these interventions may be of interest in refractory or chronic gastroparesis, with a 
significant positive clinical impact. Moreover, the endoscopic approach is simple and safe, and does not compromise further more invasive treatment.

Other therapeutic strategies are currently under development. Gastric electrical stimulators are at the research stage in the context of treatment for refractory gastroparesis in children and there are anecdotal reports of beneficial effects on symptoms and quality of life [24]. The current major advance concerns G-POEM, which was first described in 2013 for adult gastroparesis [25]. Several studies have shown its safety and efficacy for treating adult gastroparesis [26]. Because G-POEM is an emerging procedure, the ESGE recommends consideration of its use only in carefully selected patients and in expert centres in the context of a clinical trial [17]. The use of G-POEM in children should be extended before any recommendations can be made. There are currently no available data on G-POEM in the treatment of gastroparesis in children despite the use of peroral endoscopic myotomy (POEM) for pediatric achalasia [27].

In conclusion, this study shows that endoscopic pyloric dilatation and botulinum toxin injection are both safe and are equally effective for treating gastroparesis in children. Recurrence of symptoms is frequent in the first months after the procedure. These endoscopic techniques may be an acceptable treatment as the bridge between spontaneous improvement and more invasive treatment, such as G-POEM. 


\section{References}

[1] Saliakellis E, Fotoulaki M. Gastroparesis in children. Ann Gastroenterol 2013;26:20411.

[2] Waseem S, Islam S, Kahn G, Moshiree B, Talley NJ. Spectrum of gastroparesis in children. J Pediatr Gastroenterol Nutr 2012;55:166-72. https://doi.org/10.1097/MPG.0b013e31824cf06e.

[3] Edwards ST, Cocjin J, Theut SB, Rivard D, Sherman AK, Friesen CA. A comparison of the diagnosis of gastroparesis in $4 \mathrm{~h}$ pediatric gastric emptying studies versus $2 \mathrm{~h}$ studies. BMC Gastroenterol 2019;19:26. https://doi.org/10.1186/s12876-019-0948-6.

[4] Leal MC, Oliver MR, Francis P, Catto- Smith AG. Gastrointestinal: Botulinum toxin effective in refractory gastroparesis in paediatric practice. Journal of Gastroenterology and Hepatology 2015;30:232-232. https://doi.org/10.1111/jgh.12823.

[5] Chao H-C. Update on endoscopic management of gastric outlet obstruction in children. World J Gastrointest Endosc 2016;8:635-45. https://doi.org/10.4253/wjge.v8.i18.635.

[6] Kozlov Y, Kovalkov K, Smirnov A. Gastric Peroral Endoscopic Myotomy for Treatment of Congenital Pyloric Stenosis-First Clinical Experience. J Laparoendosc Adv Surg Tech A 2019;29:860-4. https://doi.org/10.1089/lap.2018.0803.

[7] Islam S. Gastroparesis in children. Curr Opin Pediatr 2015;27:377-82. https://doi.org/10.1097/MOP.0000000000000216.

[8] Claudot F, Alla F, Fresson J, Calvez T, Coudane H, Bonaïti-Pellié C. Ethics and observational studies in medical research: various rules in a common framework. Int $\mathbf{J}$ Epidemiol 2009;38:1104-8. https://doi.org/10.1093/ije/dyp164.

[9] Israel DM, Mahdi G, Hassall E. Pyloric balloon dilation for delayed gastric emptying in children. Can J Gastroenterol 2001;15:723-7.

[10] Rodriguez L, Rosen R, Manfredi M, Nurko S. Endoscopic intrapyloric injection of botulinum toxin $\mathrm{A}$ in the treatment of children with gastroparesis: a retrospective, openlabel study. Gastrointest https://doi.org/10.1016/j.gie.2011.09.042.

[11] Rodriguez L, Irani K, Jiang H, Goldstein AM. Clinical presentation, response to therapy, and outcome of gastroparesis in children. J Pediatr Gastroenterol Nutr 2012;55:185-90. https://doi.org/10.1097/MPG.0b013e318248ed3f.

[12] Coleski R, Anderson MA, Hasler WL. Factors associated with symptom response to pyloric injection of botulinum toxin in a large series of gastroparesis patients. Dig Dis Sci 2009;54:2634-42. https://doi.org/10.1007/s10620-008-0660-9.

[13] Arts J, Holvoet L, Caenepeel P, Bisschops R, Sifrim D, Verbeke K, et al. Clinical trial: a randomized-controlled crossover study of intrapyloric injection of botulinum toxin in gastroparesis. Aliment Pharmacol Ther 2007;26:1251-8. https://doi.org/10.1111/j.13652036.2007.03467.x.

[14] Friedenberg FK, Palit A, Parkman HP, Hanlon A, Nelson DB. Botulinum toxin A for the treatment of delayed gastric emptying. Am J Gastroenterol 2008;103:416-23. https://doi.org/10.1111/j.1572-0241.2007.01676.x.

[15] Thomas A, de Souza Ribeiro B, Malespin M, de Melo SW. Botulinum Toxin as a Treatment for Refractory Gastroparesis: a Literature Review. Curr Treat Options Gastroenterol 2018;16:479-88. https://doi.org/10.1007/s11938-018-0187-X.

[16] Bai Y, Xu M-J, Yang X, Xu C, Gao J, Zou D-W, et al. A systematic review on intrapyloric botulinum toxin injection for gastroparesis. Digestion 2010;81:27-34. https://doi.org/10.1159/000235917. 
[17] Weusten BLAM, Barret M, Bredenoord AJ, Familiari P, Gonzalez J-M, van Hooft JE, et al. Correction: Endoscopic management of gastrointestinal motility disorders - part 1: European Society of Gastrointestinal Endoscopy (ESGE) Guideline. Endoscopy 2020;52:C6. https://doi.org/10.1055/a-1201-7412.

[18] Pasricha TS, Pasricha PJ. Botulinum Toxin Injection for Treatment of Gastroparesis. Gastrointest Endosc Clin N Am 2019;29:97-106. https://doi.org/10.1016/j.giec.2018.08.007.

[19] Hirsch S, Nurko S, Mitchell P, Rosen R. Botulinum Toxin as a Treatment for Feeding $\begin{array}{lllll}\text { Difficulties in } \quad \text { Young Children. } & \text { J }\end{array}$ https://doi.org/10.1016/j.jpeds.2020.06.063.

[20] Heymans HS, Bartelsman JW, Herweijer TJ. Endoscopic balloon dilatation as treatment of gastric outlet obstruction in infancy and childhood. J Pediatr Surg 1988;23:139-40.

[21] Chan KL, Saing H. Balloon catheter dilatation of peptic pyloric stenosis in children. J Pediatr Gastroenterol Nutr 1994;18:465-8.

[22] Treem WR, Long WR, Friedman D, Watkins JB. Successful management of an acquired gastric outlet obstruction with endoscopy guided balloon dilatation. J Pediatr Gastroenterol Nutr 1987;6:992-6.

[23] Jawaid W, Abdalwahab A, Blair G, Skarsgard E, Webber E. Outcomes of pyloroplasty and pyloric dilatation in children diagnosed with nonobstructive delayed gastric emptying. J Pediatr Surg 2006;41:2059-61. https://doi.org/10.1016/j.jpedsurg.2006.08.005.

[24] Setya A, Nair P, Cheng SX. Gastric electrical stimulation: An emerging therapy for children with intractable gastroparesis. World J Gastroenterol 2019;25:6880-9. https://doi.org/10.3748/wjg.v25.i48.6880.

[25] Khashab MA, Stein E, Clarke JO, Saxena P, Kumbhari V, Chander Roland B, et al. Gastric peroral endoscopic myotomy for refractory gastroparesis: first human endoscopic pyloromyotomy (with video). Gastrointest Endosc 2013;78:764-8. https://doi.org/10.1016/j.gie.2013.07.019.

[26] Gonzalez J-M, Lestelle V, Benezech A, Cohen J, Vitton V, Grimaud J-C, et al. Gastric per-oral endoscopic myotomy with antropyloromyotomy in the treatment of refractory gastroparesis: clinical experience with follow-up and scintigraphic evaluation (with video). Gastrointest Endosc 2017;85:132-9. https://doi.org/10.1016/j.gie.2016.07.050.

[27] Lee Y, Brar K, Doumouras AG, Hong D. Peroral endoscopic myotomy (POEM) for the treatment of pediatric achalasia: a systematic review and meta-analysis. Surg Endosc 2019;33:1710-20. https://doi.org/10.1007/s00464-019-06701-5. 


\section{Figure legends}

Table 1 Characteristics of the patients

Table 2 Results of the treatments

Table 3 Comparison of the two treatment groups at the time of the first-line intervention 
Table 1 Characteristics of the patients

\begin{tabular}{|c|c|}
\hline & Number $(\%)$ \\
\hline Boys & $16(67)$ \\
\hline \multicolumn{2}{|l|}{ History } \\
\hline Encephalopathy & $2(8)$ \\
\hline Anti-reflux surgery & $5(21)$ \\
\hline Constipation & $4(17)$ \\
\hline Hypertrophic pyloric stenosis & $3(13)$ \\
\hline Overweight & $1(4)$ \\
\hline Age at the beginning of symptoms, years (SD) & $2.7( \pm 4.2)$ \\
\hline Weight, $\mathrm{kg}(\mathrm{SD})$ & $17.2( \pm 21.8)$ \\
\hline Z-score weight/age, mean (SD) & $-1.8( \pm 2)$ \\
\hline $\mathrm{BMI}, \mathrm{kg} / \mathrm{m}^{2}(\mathrm{SD})$ & $15.2( \pm 3.8)$ \\
\hline Z-score BMI/age, mean (SD) & $-1.5( \pm 2.5)$ \\
\hline \multicolumn{2}{|l|}{ Symptoms } \\
\hline Vomiting & $21(88)$ \\
\hline Abdominal pain & $12(50)$ \\
\hline Faltering growth & $12(50)$ \\
\hline Nausea & $5(21)$ \\
\hline Dysphagia & $5(21)$ \\
\hline Early satiety & $5(21)$ \\
\hline Respiratory symptoms & $5(21)$ \\
\hline Weight loss & $2(8)$ \\
\hline \multicolumn{2}{|l|}{ Imaging results } \\
\hline Abdominal ultrasound & $17(71)$ \\
\hline Normal & $12 / 17(71)$ \\
\hline Upper GI series & $23(96)$ \\
\hline Normal & $3 / 23(13)$ \\
\hline Delayed gastric emptying & $13 / 23(57)$ \\
\hline Gastric scintigraphy & $18(75)$ \\
\hline Normal & $1 / 18(6)$ \\
\hline Delayed gastric emptying & $16 / 18(89)$ \\
\hline Endoscopy & $24(100)$ \\
\hline Macroscopically normal & $8(33)$ \\
\hline Pylorus not passable & $6(25)$ \\
\hline Presence of food residues & $5(21)$ \\
\hline
\end{tabular}


Table 2 Results of the treatments

\begin{tabular}{|c|c|c|c|c|c|c|c|c|c|c|c|c|}
\hline & \multicolumn{6}{|c|}{ Dilatation } & \multicolumn{6}{|c|}{ Botulinum toxin } \\
\hline & Total & Partial & Failure & Unknown & Total & Recurrence & Total & Partial & Failure & Unknown & Total & Recurrence \\
\hline & success & success & & & & & success & success & & & & \\
\hline First-line treatment & 7 & 8 & 1 & 0 & 16 & 11 & 2 & 3 & 3 & 0 & 8 & 5 \\
\hline Second-line treatment & 2 & 4 & 2 & 3 & 11 & 4 & 1 & 1 & 1 & 1 & 4 & 2 \\
\hline Third-line treatment & 1 & 2 & 0 & 0 & 3 & 1 & 0 & 4 & 0 & 0 & 4 & 1 \\
\hline TOTAL, n (\%) & $10(33)$ & $14(47)$ & $3(10)$ & $3(10)$ & $30 / 46$ & $16(53)$ & $3(19)$ & $8(50)$ & $4(25)$ & $1(6)$ & $16 / 46$ & $8(50)$ \\
\hline
\end{tabular}

Success: clinical improvement during the immediate postoperative period. Total success: no more digestive symptoms after the intervention. Partial success: symptoms partially improved. Failure: unchanged symptoms and/or need for a new treatment. Recurrence: reappearance of
symptoms
at least
1 week
after
a
successful
intervention. 
Table 3 Comparison of the two treatment groups at the time of the first-line intervention

\begin{tabular}{|c|c|c|c|}
\hline & \multicolumn{2}{|c|}{ Treatment } & \multirow[t]{2}{*}{$\mathrm{p}$} \\
\hline & $\begin{array}{l}\text { Dilatation } \\
\mathrm{n}=16\end{array}$ & $\begin{array}{l}\text { Toxin } \\
\mathrm{n}=8\end{array}$ & \\
\hline Boys, n (\%) & $10(62 \%)$ & $6(75 \%)$ & 0.67 \\
\hline $\begin{array}{l}\text { Age at first intervention, } \\
\text { months, median (SD) }\end{array}$ & $45.9 \pm 57.4$ & $3.7 \pm 6.1$ & 0.3 \\
\hline $\begin{array}{l}\text { Weight at diagnosis, } \mathrm{kg} \text {, } \\
\text { mean (SD) }\end{array}$ & $21.7 \pm 25.9$ & $8.7 \pm 5.3$ & 0.26 \\
\hline First intervention & $\begin{array}{l}\text { Success: } 15 \\
\text { Failure: } 1\end{array}$ & $\begin{array}{l}\text { Success: } 5 \\
\text { Failure: } 3\end{array}$ & 0.17 \\
\hline Recurrence & $\begin{array}{l}\text { Yes: } 11 \\
\text { No: } 4\end{array}$ & $\begin{array}{l}\text { Yes: } 5 \\
\text { No: } 0\end{array}$ & 0.23 \\
\hline
\end{tabular}

